\title{
“Salva o Velho!": Relato de Atendimento em Psicologia Hospitalar e Cuidados Paliativos
}

\author{
Fabíola Langaro \\ Faculdade Guilherme Guimbala, SC, Brasil.
}

Resumo: Este trabalho apresenta o relato de atendimento de um paciente encaminhado ao serviço de atenção domiciliar de um hospital geral com diagnósticos de doenças crônicas e com indicação para tratamento em cuidados paliativos. Ao longo de um ano, a psicóloga do hospital realizou o acompanhamento do paciente junto às equipes de saúde, tanto no domicílio quanto nas hospitalizações. Foraam atendidos paciente, filhos, esposa e cuidadoras, visando auxiliar na elaboração das vivências relacionadas ao adoecimento e tratamento, bem como à busca de qualidade de vida e enfrentamento da finitude. Neste período, o paciente foi inserido, retirado e reinserido em protocolo de cuidados paliativos, devido às instabilidades no quadro clínico e aos conflitos e dificuldades de comunicação entre paciente e familiares. Neste sentido, o foco do atendimento psicológico esteve na mediação dos conflitos familiares e na comunicação paciente-família-equipes, no estímulo à autonomia do paciente, na garantia do respeito e consideração aos seus desejos e decisões, bem como ao apoio emocional para enfrentamento do luto antecipatório. As reflexões e intervenções possibilitadas pelos cuidados paliativos e pela Psicologia permitiram ao paciente não desistir da sua vida e, aos familiares, a segurança e o apoio para o enfrentamento da perda e vivência do luto.

Palavras-chave: Psicologia, Cuidados Paliativos, Atenção Domiciliar, Hospital.

\section{"Save the Elderly!": Care Report in Health Psychology and Palliative Care}

\begin{abstract}
This work presents an account of care of a patient referred to the home care service of a general hospital with diagnoses of chronic diseases and indications for treatment in palliative care. Over a year, a psychologist at the hospital performed patient follow-up with health teams, both at home and during the hospital admissions. Patient, children, wife and caregiver, aiming to help in the preparation of experiences related to illness and treatment; pursuing of quality of life and coping with finiteness were met. In this period the patient was admitted, removed and readmitted in the palliative care protocol, due to instabilities in the clinical picture and to the conflicts and difficulties of communication between him and his relatives. In this sense, the focus was on the psychological care mediation of family conflicts and on the communication patient-family - staff, stimulating the patient's autonomy, ensuring respect and consideration to his wishes and decisions, as well as giving emotional support for coping with anticipatory grief. The reflections and interventions made possible by palliative care and psychology enabled the patient not to give up his life and the family to gain security and support for coping with the experience of loss and grieving.
\end{abstract}

Keywords: Psychology, Palliative Care, Home Care, Hospital. 


\title{
“Salva al Adulto Mayor!": Relato de atención psicológica hospitalar y de cuidados paliativos
}

\begin{abstract}
Resumen: Este trabajo presenta un relato de atención psicológica a un paciente remitido al servicio de atención domiciliaria de un hospital general con diagnósticos de enfermedades crónicas e indicación para tratamiento en cuidados paliativos. Durante un año, la psicóloga del hospital realizó el seguimiento del paciente con los equipos de salud, tanto en el hogar como en las hospitalizaciones. Fueron atendidos el paciente, sus hijos, esposa y cuidadoras, con el objetivo de ayudar en la preparación de experiencias relacionadas con la enfermedad y el tratamiento, así como en la búsqueda de calidad de vida y enfrentamiento de la finitud. En este período el paciente fue insertó ingresado, retirado y reingresado al protocolo de cuidados paliativos, debido a la inestabilidad de su cuadro clínico y a os conflictos y las dificultades de comunicación con sus familiares. En este sentido, la atención psicológica se centró en la mediación de los conflictos familiares y la comunicación paciente-familia-equipo de salud, estimulando la autonomía del paciente, garantizando el respeto y consideración de sus deseos y decisiones, así como apoyándolo emocionalmente para hacer frente al luto anticipado. Las reflexiones y las intervenciones posibles gracias a los cuidados paliativos y la psicología permitieron que al paciente, no renunciar a su vida, y a la familia, la seguridad y el apoyo para hacer frente a la experiencia de pérdida y duelo.

Palabras clave: Psicología, Cuidados Paliativos, Cuidados en el Hogar, Hospital.
\end{abstract}

"As lições passadas por aqueles que estão morrendo servem para mostrar aos vivos o valor da vida" (William S. Breitbart)

\section{0 contexto}

Relata-se neste texto o atendimento psicológico realizado a um paciente e seus familiares em um serviço de atenção domiciliar e nos setores de internação de um hospital geral privado, em conjunto com as equipes de saúde daquela instituição, mais especificamente com a Equipe Multidisciplinar de Cuidados Paliativos (EMCP). O paciente foi inicialmente avaliado em sua casa e o acompanhamento se deu tanto no domicílio como no ambiente hospitalar, por ocasião de internações, pelo período de aproximadamente um ano.

O hospital geral, enquanto campo de atuação em Psicologia, compõe um cenário de diferentes demandas, que se estendem do início ao fim da vida. Inserido em uma equipe multidisciplinar, o psicólogo hospitalar tem como elementos indissociáveis de suas intervenções a interação com profissionais de outras áreas e, ainda, com o hospital enquanto instituição. De acordo com o Conselho Federal de Psicologia (2001), o psicólogo especialista em Psicologia Hospitalar participa da prestação de serviços de nível secundário ou terciário da atenção à saúde, realizando atividades como atendimento psicoterapêutico, atendimentos em ambulatório e unidade de terapia intensiva (UTI), enfermarias em geral, avaliação diagnóstica, psicodiagnóstico, consultoria e interconsultoria.

Assim, bem conhecido neste contexto é o atendimento a pacientes e familiares frente aos leitos hospitalares. Porém, ainda pouco discutido é o atendimento psicológico no domicílio enquanto parte das práticas do psicólogo hospitalar. Nestes casos, o psicólogo atende pacientes assistidos por serviços de atenção domiciliar e suas intervenções visam avaliar como pacientes e seus familiares vivenciam a situação de doença, quais os recursos psíquicos disponíveis para o enfrentamento do tratamento e do prognóstico, objetivando o suporte e a ampliação de recursos emocionais. Busca compreender a dinâmica familiar e seu modo de organização para o tratamento, para então elaborar um plano de apoio que contribua para o enfrentamento da doença e do contexto de cuidados domiciliares. Ainda, o psicólogo auxilia a equipe multiprofissional a compreender a psicodinâmica do paciente e dinâmica de relacionamento 
familiar, facilitando o relacionamento e a comunicação paciente-família-equipe.

Conforme descrevem Yamaguchi e Oliveira (2011), a assistência ou atenção domiciliar (home care) se destina a pacientes com limitações para locomoção até centros de tratamento, oferecendo grande parte dos cuidados crônicos no domicílio, numa tentativa de preservar a intimidade e oferecer conforto a pacientes e familiares. Caracteriza-se por ações interdisciplinares em resposta a uma avaliação global e tem entre seus principais objetivos a integralidade, o reforço da autonomia, a humanização dos serviços de saúde, a comunicação efetiva e a qualidade de vida. Já os cuidados paliativos podem ser definidos como uma abordagem que aprimora a qualidade de vida dos pacientes e familiares que estão em um processo de adoecimento sem perspectivas de cura, a fim de favorecer o acesso à informação e o suporte através da prevenção e identificação precoce e tratamento da dor e de outros sintomas de ordem psicossocial e espiritual de modo a aliviar o sofrimento (ANCP, 2012).

Dessa forma, considera-se que o domicílio, por meio da atenção domiciliar em saúde, pode ser ambiente propício ao exercício de práticas em cuidados paliativos. É indispensável, porém, avaliar as condições que cada paciente e família possuem para que estes cuidados sejam exercidos e mantidos neste local até o fim da vida. Nesse sentido, as interações que ocorrem entre o hospital e o serviço de atenção domiciliar são fundamentais para que se cumpra um dos principais objetivos dos cuidados paliativos: influenciar o tipo de morte que o paciente terá (ANCP, 2012).

No referido hospital, a EMCP é formada por um conjunto de profissionais que, além de realizarem suas atividades de trabalho nos setores do hospital e/ou no serviço de atenção domiciliar, atendem pacientes a partir da perspectiva dos cuidados paliativos. A equipe conta, portanto, com médicos, psicólogas, enfermeiras, técnicos de enfermagem, fisioterapeutas, terapeuta ocupacional, farmacêutica e pedagoga hospitalar, atuando de modo complementar e em caráter de consultoria, em conjunto com as equipes assistenciais. A inserção em protocolo de cuidados paliativos pode ser realizada no hospital ou no domicílio e, sempre que há transferência do paciente de um destes locais para o outro, a EMCP dá continuidade ao acompanhamento, porém muitas vezes realizando novas reuniões e replanejando metas de tratamento.
Considerando a riqueza dos elementos envolvidos no atendimento psicológico realizado ao paciente e familiares nos contextos intra e extra-hospitalar, este artigo apresenta um estudo do caso do paciente aqui denominado Pedro. Esta metodologia de pesquisa consiste na busca de um conhecimento profundo e exaustivo que visa permitir uma ampla visão do funcionamento do fenômeno em questão, estabelecendo possíveis relações entre variáveis de um sistema complexo (GIL, 2008). Quando ligada à prática psicoterapêutica, caracteriza-se pela reconstrução da história do indivíduo. Dessa forma, relatos clínicos são frequentemente realizados com o objetivo de descrever, informar, compartilhar experiências e ilustrar teorias e técnicas, demonstrando a plausabilidade das mesmas (Serralta, Nunes \& Eizirik, 2011).

Para tanto, as informações foram coletadas por meio da revisão do prontuário multidisciplinar do paciente e do registro em prontuário psicológico. Após a descrição da trajetória do paciente nos serviços de saúde, as ações psicoterapêuticas realizadas e os resultados obtidos foram analisados a partir da literatura relacionada ao contexto hospitalar, atendimento psicológico e cuidados paliativos.

\section{O encontro com Pedro - no domicílio}

Pedro tinha 64 anos, era profissional de educação física e estava aposentado. Morava com Joana, esposa de segundo casamento, tinha dois filhos adultos, Marcos e Gabriela, residentes em outras cidades. Contava com auxílio de cuidadoras formais que, ao longo do acompanhamento, demonstraram oferecer importante apoio e suporte emocional, participando ativamente das rotinas e interagindo constantemente com as equipes de saúde. Joana era também profissional de educação física, estava aposentada e tinha filhos do primeiro casamento. Ana, a cuidadora que mais ativamente participou dos cuidados e por mais tempo permaneceu com Pedro, era auxiliar de enfermagem e tinha aproximadamente 40 anos.

Quando inserido no serviço de atenção domiciliar, Pedro tinha como diagnósticos: demência por corpúsculos de Lewy, acidentes vasculares cerebrais prévios, hipertensão arterial, doença pulmonar obstrutiva crônica, dislipidemia, apneia do sono, dor crônica por estenose medular, traqueostomia e, posteriormente, gastrostomia. Estava em uso de bipap (respirador mecânico não invasivo) domiciliar no 
período noturno. Durante o período de acompanhamento no domicílio, permanecia deambulando com auxílio. Necessitava, portanto, de cuidados para suas condições crônicas de saúde. Também sua família e cuidadoras, a partir do agravamento contínuo de suas doenças, passaram a ser constantemente informadas e capacitadas para os cuidados.

A equipe da atenção domiciliar era composta por médicos, enfermeiros, técnicos de enfermagem, terapeuta ocupacional, fisioterapeutas e psicóloga. Embora realize ações de reabilitação, este serviço também conta com um protocolo sistematizado de cuidados paliativos, oferecendo suporte a pacientes e familiares com diagnósticos de doenças que ameaçam a continuidade da vida, como no caso de Pedro.

Em consulta médica domiciliar inicial, o paciente estava acamado, sem responder a estímulos verbais. Observou-se que ele e a esposa não haviam recebido informações acerca da possibilidade do tratamento paliativo, apesar de seus diagnósticos terem indicação para tal. Com as orientações fornecidas pelo médico, a esposa mostrou-se favorável a esta modalidade de atendimento, porém o paciente rejeitava quaisquer sugestões que pudessem melhorar sua qualidade de vida. Diante deste panorama, o médico solicitou avaliação da psicóloga do serviço, com o objetivo de oferecer suporte emocional ao paciente e à esposa e dar continuidade à orientação quanto à busca de mais qualidade de vida para ambos.

Em avaliação psicológica domiciliar inicial, o paciente apresentava sintomas depressivos, principalmente desânimo e desesperança. Porém, mostrava-se lúcido, orientado, comunicativo e receptivo ao atendimento. Segundo a esposa e cuidadoras, estava agitado, irritado e lábil emocionalmente. Mostrava-se pessimista, resignado e passivo quanto ao seu estado de saúde. Acreditava que nada poderia ser feito e não realizava esforços para alterar sua condição existencial. Vivenciava conflitos no relacionamento com a esposa e isto o deprimia mais. Ambos apresentavam dinâmica de competição/disputa e de pouco apoio emocional mútuo. A esposa referia que o neurologista havia informado sobre terminalidade do quadro e, desde as primeiras visitas da equipe, dizia que "o paciente tinha pouco tempo de vida e que estava demenciado".

Nos primeiros atendimentos psicológicos, o paciente, sempre lúcido e orientado, queixou-se de estar morando na casa da esposa (anteriormente viviam em casas e cidades distintas, sendo a dele em uma praia). Dizia sentir saudades do seu cachorro, queria estar na sua casa, pois "sentia-se preso" no apartamento de aproximadamente $60 \mathrm{~m}^{2}$ onde estava morando. Mostrava dificuldades de aceitação e enfrentamento ao processo de adoecimento. Sua dinâmica psicológica apontava para passividade, sentimento de autopiedade, irritabilidade, autoritarismo e racionalidade como estratégia de defesa frente ao sofrimento.

Observava-se que o adoecimento era vivido com extremo sofrimento por Pedro, pois, até então, não havia se deparado com tamanha vulnerabilidade e com a inevitabilidade da finitude. Vivia sem dar-se conta de que um dia envelheceria e de que, como qualquer outra pessoa, poderia adoecer. Além disso, vivenciava o luto por diversas perdas diárias: "da autonomia, do corpo saudável, da imagem corporal [...] do seu papel dentro da família, enfim, da possibilidade de prosseguir em seus planos e sonhos" (Macieira \& Palma, 2011, p. 327). Enfrentava, portanto, um luto antecipatório, visto que diversas perdas foram sendo experienciadas antes da morte. Este processo ocorreu tanto para Pedro quanto para seus familiares, em particular pelos seus filhos. Neste sentido, o favorecimento da expressão dos sentimentos que acompanharam estas perdas tornou-se fundamental no cuidado ao paciente e sua família (Kovacs, 2007).

Como consequência da dor psíquica frente ao adoecer, Pedro mostrava sentimentos de raiva e revolta. Dando-se conta de sua debilidade e limitações, claramente percebia as perspectivas de morte, vivendo um sentimento de grande perda. Neste sentido, a partir do diagnóstico de uma doença grave, ameaçadora da vida, observam-se reações de negação, barganha, raiva/revolta, depressão e aceitação. Aceitação compreendida não como resignação, mas como relação com o adoecimento que envolve uma compreensão real dos limites e das possibilidades impostas pela doença, flexibilidade para lidar com as limitações, ansiedade em nível suportável para o paciente, família e equipe e participação ativa no tratamento (Kübler-Ross, 2011). Aceitação esta nem sempre possível, mas almejada pelo atendimento psicológico hospitalar em cuidados paliativos.

De acordo com Breitbart (2011), um dos objetivos da psicoterapia com pacientes terminais é ajudá-los a atingir um senso de aceitação da vida e, assim, de aceitação da morte. Os esforços que envolvem o 
fechamento da vida são atingíveis e essenciais nesse momento e reconhecer ou aceitar a morte podem ser um impulso para a transformação. Além disso, o estímulo à expressão de sentimentos e desejos tem o intuito de possibilitar a realização de metas no tempo de vida ainda restante (Menezes, 2011).

Este processo dependerá, porém, não somente dos recursos emocionais construídos na relação psicoterapeuta-paciente, mas também das estratégias de enfrentamento disponíveis pelo sujeito no momento do adoecimento. Estas estratégias têm relação com a habilidade de os sujeitos lidarem com circunstâncias difíceis de vida e possibilitam a ele alterar o ambiente, adaptando-se a circunstâncias adversas (Silva, Siqueira, Stroppa \& Moreira-Almeida, 2011). Portanto, relacionam-se à história de vida, a experiências anteriores de estresse e insegurança existencial e estão atreladas ao sentido que o sujeito dá à vida e ao evento adverso - neste caso, o adoecimento.

Espiritualidade, família e amigos podem servir como importante apoio nestes momentos de crise e ser acionados enquanto estratégias de enfrentamento. Contudo, "a experiência de adoecer e a iminência da morte são frequentemente causadoras de grande estresse e sofrimento psicológico para o indivíduo e seus entes queridos" (Silva et al., 2011, p. 176). Joana não conseguia oferecer suporte emocional ao marido, em parte porque ela mesma apresentava sintomas de esgotamento emocional, pelo longo período e difícil contexto de cuidados e, ao mesmo tempo, por suas características pessoais, que a levavam a buscar estar no controle das situações relacionadas ao marido. Assim, não dividia responsabilidades, determinava como seria a dinâmica da casa e dos cuidados diretos a Pedro. Dava a ele pouca autonomia, constantemente conversava sozinha com médicos e tomava decisões sem consultá-lo. Sobrecarregava-se e, ao mesmo tempo, o desestimulava a participar ativamente de seu autocuidado.

Neste sentido, os objetivos principais do acompanhamento psicológico e também da equipe do serviço de atenção domiciliar eram resgatar a autonomia de Pedro, estimulá-lo a tornar-se ativo e participativo de seu tratamento e, finalmente, possibilitar que seus desejos fossem, tanto quanto possível, realizados. Contudo, isto requeria também o trabalho com sua família, em especial com Joana, visto que o cuidado com esta unidade paciente-família influencia significativamente não somente a qualidade de vida durante o adoecimento, mas também o luto que se instala após a perda do ente querido. Neste processo, o suporte às cuidadoras formais foi também realizado pela equipe, uma vez que todas, mas principalmente Ana, construíram importante vínculo com o paciente, tendo sido fonte fundamental de apoio não só para os cuidados, mas também emocional.

\section{Uma grande mudança}

Nos atendimentos psicológicos seguintes, em frequentes tentativas de diálogo do casal, mediadas pela psicóloga, Joana mostrava-se resistente à mudança de Pedro para a casa na praia, seu maior desejo expresso em psicoterapia. Queixava-se longamente do comportamento do marido e mostrava preocupação com relação à assistência que poderia ser acessada em caso de agravamento do quadro, tendo em vista que lá não havia hospital e que o município estava fora da área de abrangência do serviço de atenção domiciliar.

Por diversas vezes foi realizado atendimento psicológico para mediar conflitos do casal e buscar de maneira conjunta formas de melhorar a qualidade de vida de ambos. Também foram realizados atendimentos separadamente: à esposa visando atenuar esgotamento e estimular autopercepção quanto à sua própria dinâmica psicológica; e ao paciente para estimular a construção de recursos de enfrentamento ao adoecimento, bem como a manter-se autônomo e participativo em seu processo de tratamento, visto que estava "entregue" à situação e não enxergava possibilidades de melhora em sua condição de vida. Ao médico, havia dito que "seria melhor morrer do que continuar vivendo desta forma”.

Após três meses de frequentes mediações de diálogos, Pedro apresentava melhora no humor, no enfrentamento ao adoecimento e também aos conflitos com Joana. Estava menos irritado, mais colaborativo com as cuidadoras e já tomava iniciativa de conversar com a esposa e de aproximar-se emocionalmente dela. Em um atendimento chegou a dizer que "inicialmente ela conversava $10 \%$ de coisas comigo e agora fala 30\%". Apesar deste avanço, não parecia haver perspectiva de que Joana concordaria com a mudança de domicílio para a praia. Em meio a este processo, o filho do paciente, Marcos, chegou a ser comunicado sobre estes acontecimentos, sobre o desejo do pai e das dificuldades que a equipe enfrentava para viabilizar sua vontade. O filho informou 
que tentaria acompanhar mais de perto a situação e cogitou possibilidade de mudança de Pedro para a casa de Gabriela. Apesar da evolução do quadro emocional de Pedro, observou-se que o retorno para sua casa seria essencial para assegurar conforto e melhor qualidade de vida.

Por este motivo, a equipe interdisciplinar discutiu o caso e, havendo concordância de que seria importante realizar intervenções visando a mudança, os profissionais passaram a tentar viabilizar a concretização do desejo do paciente: o médico tranquilizou a esposa quanto à liberação para mudança de cidade, orientou sobre como proceder em caso de urgência ou emergência, pois havia uma unidade de pronto atendimento 24 horas próxima à residência no litoral; as enfermeiras auxiliaram nas providências para transferência de aparelhos respiratórios e demais instrumentos de cuidados; a psicóloga reforçou a importante decisão de respeitar o desejo do paciente de voltar para sua casa, mantendo sua autonomia, possibilitando retorno ao seu espaço de vínculos e história pessoal e sobre o impacto emocional benéfico que isto teria.

Dessa forma, Joana foi orientada quanto ao princípio da ortotanásia, ou seja, de que as ações terapêuticas poderiam ser aplicadas apenas na medida de sua eficácia, evitando sofrimento extra ao paciente, aceitando a morte como uma condição humana (ANCP, 2012). Neste sentido, mesmo que Pedro viesse a falecer na praia, isto não significaria negligência de cuidados, nem apressamento de sua morte, mas consequência do agravamento de suas doenças. Considerando que a morte seria inevitável diante do quadro clínico, pensar na qualidade dos dias - e não na quantidade - era uma forma de possibilitar que o paciente vivesse até o dia de sua morte conforme seu desejo e sua biografia. Assim, a equipe buscava aplicar os princípios dos cuidados paliativos de afirmar a vida e considerar a morte um processo natural; não apressar, nem retardar a morte; integrar os aspectos psicossociais e espirituais ao cuidado do paciente; oferecer sistema de apoio com o intuito de ajudar o paciente a viver ativamente tanto quanto possível até a morte; e oferecer sistema de apoio para ajudar a família a lidar com a doença do paciente (ANCP, 2012).

Apesar deste investimento na tentativa de garantir a prevalência do desejo de Pedro, da resistência inicial da esposa e dos conflitos do casal, a equipe teve habilidade de mediar conflitos e manter vínculo com ambos. Neste processo, a partir dos esclarecimentos realizados e pela confiança conquistada pelos profissionais, bem como pelo tempo e suporte oferecido para que a esposa estivesse segura quanto à mudança de foco terapêutico e das decisões sobre priorizar a qualidade de vida do paciente, Joana passou a considerar a possibilidade de transferência de domicílio, sentindo-se segura para tal e reorganizando sua forma de cuidados a Pedro.

Neste momento, o paciente novamente mostrou-se pessimista, dizendo "vamos ver se isso vai dar certo, vou esperar, mas acho que não vai dar". Neste momento, a psicóloga reforçou que a mudança somente poderia ocorrer caso houvesse um esforço conjunto de todos os envolvidos no processo, inclusive do paciente. Considerando posição frequente de autopiedade assumida pelo paciente, a psicóloga reforçou que a posição da equipe era de confiança em suas potencialidades e de que todos precisavam atuar conjuntamente para que os resultados fossem alcançados. Considerando que o paciente havia sido árbitro, utilizou-se da seguinte metáfora:

pela sua experiência, o senhor deve saber que, quando um time muito bom entra em campo para jogar com um time não tão bom, se este segundo achar que já está derrotado e entrar com este sentimento em jogo, a derrota será quase inevitável. Porém, há muitos casos em que, mesmo com nível inferior, se o time mais fraco entrar em campo acreditando que a vitória é possível, ela de fato será. Não coloque um time perdedor em campo.

O paciente reagiu muito bem a esta metáfora e passou a colaborar mais para a transferência para a praia, que foi programada para o final daquele mês.

Antes da mudança, uma nova visita foi realizada, para encerramento do atendimento pelo serviço de atenção domiciliar. Neste dia, o paciente emocionou-se muito e agradeceu à equipe pela assistência e à psicóloga pelas intervenções, referindo que "antes de te conhecer eu só queria morrer. Mas agora não, agora eu quero viver!”. Verificava-se, em suas falas, importante vínculo estabelecido com a equipe, sendo este elemento, portanto, instrumento fundamental para as intervenções realizadas ao longo de todo o atendimento, tanto com Pedro como com Joana e as cuidadoras. Vínculo 
aqui compreendido como ligação que envolve afetividade, ajuda e respeito, capaz de estimular a autonomia. Assim, criar vínculos implica ter relações próximas e claras, que possibilitam ver pacientes e familiares como sujeitos, ouvi-los e compreendê-los em suas necessidades e estabelecer uma relação de cooperação e corresponsabilidade pelas ações em saúde (Schimidt \& Lima, 2004).

\section{Idas e vindas - no hospital}

Poucos dias antes da transferência de domicílio, o paciente teve infecção no trato urinário pelo uso frequente de sonda de alívio e precisou ser hospitalizado na UTI. Devido à gravidade do quadro e às doenças de base, as equipes assistenciais optaram por reafirmar a inserção do paciente em protocolo de cuidados paliativos, agora naquela unidade. Ao ser consultada sobre as decisões terapêuticas, Joana concordou que fossem realizadas somente medidas de conforto e referiu que esta era também a decisão dos filhos de Pedro. Antes de registrar estas orientações em prontuário, a EMCP tentou contato com os filhos, considerando a importância de sua participação nestas decisões, porém não conseguiu localizá-los. Sob cuidados paliativos, apesar da gravidade do quadro, alguns dias após internação na UTI o paciente recuperou-se da infecção e em 20 dias teve condições de alta. Finalmente, então, mudou-se para a cidade litorânea.

Após ter permanecido um mês em sua nova casa, o paciente foi novamente hospitalizado por infecção urinária. Na chegada ao pronto atendimento, Ana, cuidadora que o acompanhava, informou ao médico plantonista a decisão da família sobre tratamento paliativo. Porém, o profissional solicitou a presença dos familiares para confirmar a informação e consultar Pedro acerca de suas escolhas quanto às terapêuticas. Depois deste episódio, Joana e Ana procuraram pela psicóloga e, em conjunto com ela, optaram por realizar nova abordagem para discussão sobre as metas de tratamento. Nestes dias, o filho do paciente veio visitá-lo, quando então a psicóloga informou sobre a intenção de promover este diálogo. Marcos mostrou-se receptivo e solicitou que todas as conversas fossem realizadas junto com Pedro, que se recuperava bem da infecção e, devido à presença do filho e recente mudança para a praia, apresentava melhora no humor e na interação com o meio.
Sobre este pedido de Marcos, cabe lembrar que:

para que uma equipe de cuidados paliativos cumpra de fato seu papel, não pode agir dentro dos moldes paternalistas que a medicina tradicionalmente vem adotando. Quem está morrendo se estiver consciente, tem o direito de ser considerado como sujeito, aliás, como ator principal, e o cuidador, que está ao seu lado, partilhando a dor da partida, pelo menos como ator coadjuvante [...] [o que significa] 1) fornecer o máximo de informações possíveis, tomando o cuidado de dosá-las com apoio psicológico, no momento adequado, sensível à medida com que os indivíduos desejam ser informados; 2) discutir as decisões terapêuticas e engajá-los a tomar parte nessas decisões [...] (Incontri, 2011, p. 147).

Assim, o paciente, que permanecia nos setores de internação, foi abordado quanto à mudança de foco terapêutico para cuidados paliativos, tendo sido informado sobre reafirmação da inserção em protocolo na hospitalização anterior, quando estava na UTI. Após explicações sobre objetivos e metas de tratamento e implicações quanto a não realização de procedimentos invasivos (reanimação, internação em UTI, intubação), o filho referiu que sabia desta mudança de foco, porém não estava ciente quanto à decisão de Joana sobre não realizar medidas invasivas de tratamento.

O paciente e seu filho foram, em alguns atendimentos com a psicóloga em separado e também em conjunto com enfermeira e o médico da equipe de cuidados paliativos, orientados sobre esta filosofia de tratamento, bem como da importância de refletir sobre decisões quanto ao final de vida. A todo o momento, foi garantido que seu desejo seria respeitado e que havia a intenção das equipes em conhecer suas diretrizes antecipadas de vontade. Diante da comunicação sincera com o filho e o paciente, questionado quanto ao seu desejo, Pedro referia compreender a gravidade e progressão das doenças, sem possibilidade de cura, porém solicitou: "Salva o velho!".

Desejava, assim, que todo investimento em terapêuticas curativas fosse realizado e que sua vida fosse prolongada. Solicitava que as equipes realizassem todo o possível para manter sua vida e salvá-lo da morte. Após anos de adoecimento e de longo período em que não encontrava sentido para sua existência, 
Pedro havia aprendido a valorizar seus dias, a companhia dos filhos, a presença amorosa das cuidadoras e o cuidado atencioso das equipes de saúde. Havia construído novos sentidos para suas experiências e a tristeza anterior de estar vivo transformara-se: agora sentia-se triste por pensar em "abandonar" este mundo e, por isso, solicitava que nenhum esforço deixasse de ser realizado para que pudesse continuar usufruindo de suas novas conquistas.

Diante deste pedido, o médico da equipe de cuidados paliativos realizou nova avaliação do paciente, incluindo aplicação do mini exame do estado mental, em que constatou que Pedro não apresentava sinais indicativos de demência, estando lúcido e orientado, bem como o questionário Confusion Assessment Method (CAM), em que não detectou presença de delirium, o que o tornava apto a tomar decisões sobre sua doença e tratamento. Conversou com ele novamente sobre quadro clínico e prognóstico, quando mostrava-se ciente da gravidade. Porém, reforçou que se necessário desejava que fossem realizadas todas as medidas de tratamento, inclusive as invasivas. O médico conversou com Pedro, Joana e as cuidadoras que seriam mantidas as vontades do paciente $\mathrm{e}$ que o acompanhamento da equipe de cuidados paliativos, a partir de então, seria realizado somente caso houvesse alguma mudança no quadro e nova solicitação do médico assistente para reavaliação.

Assim, a comunicação é um dos pilares da Medicina Paliativa. O mais importante não é exatamente o que dizer e sim como fazê-lo. Pode-se começar ouvindo o que o paciente já sabe, para fornecer as informações que ele consegue integrar de acordo com seu grau de entendimento (Costa Filho, Costa, Gutierrez \& Mesquita, 2008). Neste sentido, a comunicação é a base para a confiança na equipe, visto que famílias revelam que uma comunicação inconsistente é uma das suas maiores preocupações. A falta de clareza e profundidade faz com que familiares reportem dissabores e ansiedade pela forma com que seus entes estão sendo tratados (Costa Filho et al., 2008, p. 90).

Finalmente, outro aspecto indispensável para que se realizem cuidados paliativos de qualidade é o respeito e o incentivo à autonomia do paciente, sendo este um dos princípios da bioética. A autonomia refere-se à possibilidade de escolha individual, ao direito que a pessoa tem de tomar decisões que afetem sua vida. Ao decidir o que é bom, o que é o seu bem-estar, a pessoa age de acordo com seus valores, suas necessidades e prioridades, demarcando qual a sua vontade frente à realidade que vivencia. A possibilidade de escolha é o alicerce da autonomia e, para que se concretize, é preciso que existam alternativas de ação. Se existe um único caminho a seguir não existe possibilidade de exercício de autonomia (Medeiros, 2002).

Assim, após diversos diálogos com o Pedro, seus familiares e cuidadoras, o paciente foi retirado de protocolo de cuidados paliativos, a equipe assistencial foi informada sobre esta decisão compartilhada, as informações foram registradas e salientadas em prontuário, respeitando-se a decisão de Pedro de investir em terapêuticas mesmo que isto levasse a prolongar sua vida artificialmente. Inclusive, na presença da equipe, a cuidadora questionou o paciente: "o senhor entende que, caso precise ir para a máquina de ventilação mecânica, pode não sair mais, ficando dependente dela?". Ainda assim, o paciente solicitou: "Salva o velho!". Mais: referiu que desejava ser informado sobre tudo o que fosse relacionado ao seu quadro e tratamento, direito este garantido pelo Código de Ética Médica.

\section{O recomeço e o fim}

Após a interrupção do acompanhamento pela EMCP, o acompanhamento psicológico teve continuidade durante as quatro hospitalizações que se seguiram ao longo dos seis primeiros meses daquele ano, devido ao importante vínculo estabelecido e ao impacto que as intervenções demonstraram ter na qualidade de vida de Pedro. Em todas elas, o paciente, as cuidadoras, a esposa e, progressivamente, os filhos, foram acompanhados pela psicóloga.

Tornaram-se frequentes os diálogos de incentivo à convivência com familiares e amigos, realização de desejos, estímulo à qualidade de vida, com passeios ao sol e caminhadas próximas ao mar. Mesmo não inserido formalmente em protocolo de cuidados paliativos, o objetivo continuava sendo buscar que o paciente vivesse o mais intensamente possível até o dia de sua morte. Os encontros eram recheados por histórias e anedotas bem-humoradas contadas por Pedro, que se emocionava nos momentos de alta hospitalar, agradecendo pelas intervenções realizadas. Neste período, apesar das dificuldades de relacionamento com a esposa, optou por dar continuidade ao casamento. Havia aprendido a compreendê-la e aceitá-la em sua maneira de ser.

Os colaboradores do hospital, principalmente o fisioterapeuta que o acompanhava desde início do 
adoecimento, comentavam sobre a mudança de comportamento do paciente: de alguém impaciente, não colaborativo, mal-humorado, não receptivo, passou a ser grato pelo trabalho realizado pelos profissionais, tornou-se ativo em seu tratamento, realizando com vontade as terapêuticas indicadas.

Em todos os atendimentos, Pedro mostrava-se lúcido, orientado, ciente de todas as intervenções realizadas. Por este motivo, as diversas avaliações realizadas pelos médicos que o acompanharam em cuidados paliativos e no serviço de atenção domiciliar, bem como avaliações dos demais profissionais, fizeram discordar do diagnóstico de demência. Porém, a esposa do paciente continuava referindo que a doença progredia e que o paciente estava cada vez mais confuso e sem lucidez. Com a participação mais efetiva e constante dos filhos nos cuidados, os conflitos pré-existentes entre filhos e esposa se intensificaram, tendo Marcos e Gabriela inclusive solicitado nova avaliação médica quanto ao quadro neurológico, quando então o médico assistente, durante uma das internações, atestou lucidez, consciência e orientação adequadas e incompatíveis com demência.

No início da quarta hospitalização após a mudança para a praia, o paciente comentava o fato de, nos últimos meses, ter saído cinco vezes da UTI. Isto reforçava seu desejo de que todo investimento em tratamentos curativos fosse realizado. Passados alguns dias desde a entrada no hospital, porém, esteve muito próximo a ter uma parada cardíaca. Sua pressão arterial e frequência cardíaca haviam diminuído consideravelmente, bem como seu nível de consciência. Diante deste quadro, médica assistente conversou novamente com a esposa e os filhos sobre possibilidade de retomada dos cuidados paliativos. Embora a esposa concordasse, Marcos e Gabriela, impactados pelos conflitos com Joana, não concordaram com a mudança de foco.

Neste momento, a equipe de enfermagem mostrou-se ansiosa e questionou a psicóloga "quanto ao que fazer em caso de parada cardíaca”. Considerando a retirada do paciente do protocolo de cuidados paliativos a seu pedido, a orientação era de realizar reanimação e isto foi reforçado. Porém, diante da progressiva aproximação e do vínculo com os filhos, a psicóloga conversou com Marcos a respeito da possibilidade desta intercorrência, estimulando-o a falar novamente com a médica assistente, sem a presença de Joana, para retirar dúvidas e considerar consequências de uma possível reanimação. Assim sendo, o filho conversou com a médica e, após seus esclarecimentos, passou a considerar a possibilidade de mudança de foco terapêutico.

Por diversos dias o paciente permaneceu comatoso na unidade de internação, com resposta somente a estímulos dolorosos, e o filho compreendia a gravidade do quadro. Porém, referia dificuldade da irmã em aceitar a possível perda do pai. Por morar em outra cidade e visitar o paciente somente aos finais de semana, $\mathrm{o}$ atendimento psicológico à Gabriela não pôde ser realizado neste período, dificultando a avaliação de sua relação com o adoecimento e o prognóstico das doenças de Pedro. Ainda assim, por diversas vezes, a psicóloga orientou Marcos sobre importância de manter Gabriela informada dos diálogos com a equipe e das reflexões e esclarecimentos realizados.

Após alguns dias nesta condição de piora clínica, o paciente teve nova melhora e voltou a interagir, embora tivesse significativa dificuldade na fala. Ainda assim, tão logo quanto possível, foi novamente questionado sobre seu desejo quanto às terapêuticas, quando reforçou: "Salva o velho!". Embora as terapêuticas curativas tenham sido mantidas, diante deste pedido veemente de Pedro, a psicóloga avaliava o medo intenso de morrer do paciente. Em um dos atendimentos posteriores, o questionou sobre como compreendia sua doença naquele momento e ele disse "estar chegando...", referindo-se ao agravamento do quadro e à proximidade da morte. Foi então abordado sobre como se sentia, quando chorou intensamente, mas agradeceu por tudo o que havia sido feito por ele.

Sentia-se grato, porém não queria deixar a vida. Preocupava-se com os filhos, não sabia como pensar sobre a morte, "nunca havia desenvolvido sua espiritualidade". A psicóloga reforçou o desenvolvimento pessoal ocorrido desde o início do acompanhamento psicológico, bem como o crescimento e mudança ocorridas em sua forma de viver e de se relacionar com o adoecimento e com as pessoas. Além disso, foi lembrado de que sim, as equipes realizariam todos os esforços necessários para "salvar o velho", mas que, em algum momento, as possibilidades também se esgotariam... Assim, conforme descreve Santos (2011, p. 457),

da perspectiva do desenvolvimento intelectual, cultural e espiritual, os pensamentos, sentimentos, experiências e atividades durante os últimos meses, dias e momentos da vida da pessoa que 
está morrendo podem ser mais importantes do que onde e como a pessoa morre ou as causas da morte. [...] A presença da finitude e o aparecimento de oportunidades de crescimento, mesmo no fim da vida, talvez sejam os últimos grandes desafios para o desenvolvimento da psique ou do espírito. [...] A fase do morrer de nossas vidas pode ser vivenciada como um dos eventos de mais crescimento que poderíamos experimentar na nossa jornada ao longo da vida.

Nesse período, por meio do atendimento a Marcos, a psicóloga verificou que Gabriela empenhava-se, em sua vida pessoal, a desenvolver de maneira bastante intensa sua espiritualidade. Ponderou com ele sobre a possibilidade dela compartilhar com o pai suas crenças, para construir com ele significado para a vida e para a morte, visto que este processo pode aumentar o bem-estar espiritual e diminuir a possibilidade de desespero ao final da vida (Breitbart, 2011). Além disso, orientou sobre a possibilidade de o paciente receber acolhimento espiritual, por meio do agendamento de visita ao hospital, quando Marcos informou que um religioso amigo da família já havia conversado com o paciente, oferecendo-lhe este suporte.

Observava-se que filhos mostravam-se participativos, compreensivos, desejosos de entender os sentimentos do pai e auxiliá-lo a enfrentar os momentos finais de vida. Assim, foram informados sobre o medo de Pedro diante da morte e do seu apego pela vida, para que, após a alta hospitalar, que já estava programada, pudessem continuar mediando suas reflexões e oferecer suporte emocional a ele. Assim, possibilitar a Pedro o enfrentamento da morte poderia aprimorar o processo de busca por significado e encerramento da vida, permitindo a ele a oportunidade de aproveitar seu potencial ao máximo, de deixar para trás um legado autêntico e de conectar-se com o que está além, de transcender (Breitbart, 2011). Nesta busca,

o objetivo é preservar a ideia de que ainda há vida a ser vivida, de que ainda há tempo pela frente, para que o indivíduo possa morrer com um senso de paz, equanimidade e aceitação da vida que viveu. O paradoxo da dinâmica da fase terminal é que por meio da aceitação da vida que foi vivida vem a aceitação da morte (Breitbart, 2011, p. 140).
Decorridos 20 dias após a alta desta internação, o paciente retornou ao hospital, com nova infecção no trato urinário. Além do tratamento com antibióticos, seria realizada troca de traqueostomia. Assim, numa sexta-feira, poucos dias após hospitalização, a psicóloga visitou o paciente no leito. Depois de alguns instantes de atendimento, em que Pedro falava sobre as dificuldades no relacionamento com a esposa e de consequentes decisões tomadas, inclusive em termos legais, chegaram seus filhos. Decorreu então um encontro em que Marcos e Gabriela mostraram à psicóloga as fotos de Pedro com seu cachorro em sua casa, na praia, bem como fotos antigas, do paciente ainda criança, sentado com seus irmãos e empunhando chocolates de páscoa. O paciente contava tudo: onde estava, com quem estava, como era sua vida, como havia sido a infância e a adolescência... Mostrava-se feliz pelo momento, lembrando de boas experiências da vida. Muitos sorrisos e histórias divertidas foram compartilhadas. Ter olhado para o passado por meio do relembrar antigas memórias era uma possibilidade de dar razão para sua existência junto aos sues próximos, sendo parte de um processo de aceitação da morte. Por meio de suas lembranças e memórias, na presença de seus familiares, Pedro encontrou paz e conforto (Corrêa, 2011).

Foi uma despedida. Naquela madrugada, Pedro teve uma parada cardíaca. Embora tenha sido reanimado após apenas três minutos, retornou à vida em estado vegetativo. Foi levado à UTI, permanecendo neste setor por cinco dias, quando os filhos continuaram sendo acompanhados pela psicóloga. Diante da irreversibilidade e agravamento do quadro, Marcos e Gabriela intensificaram a elaboração de um luto antecipatório. De alta da UTI, o paciente foi encaminhado ao setor e, após dois dias, médica assistente solicitou nova avaliação da equipe de cuidados paliativos. Embora o médico paliativista estivesse receoso quanto a esta nova abordagem, pelo histórico anterior de inserção e retirada em protocolo, psicóloga sabia que, neste momento, os filhos estariam abertos a este novo diálogo e acompanhou médico neste encontro.

Em conversa com a psicóloga e com o médico da equipe de cuidados paliativos, os filhos foram enfáticos sobre desejo de não realizar nova reanimação ou outros procedimentos invasivos de tratamento, pois referiam que "o pai não desejava permanecer assim", ou seja, o paciente após as intervenções realizadas, havia referido que, caso chegasse àquele estado, não 
desejava que sua vida fosse prolongada. Até o último momento, portanto, Marcos e Gabriela optaram por respeitar os desejos do paciente.

Durante os dias seguintes, Pedro permaneceu irresponsivo, porém mudou sua feição: inicialmente tinha uma expressão, segundo Marcos, "de brabeza". Aos poucos, apresentava uma face serena. Após cinco dias da inserção em protocolo de cuidados paliativos, na presença de uma das cuidadoras, de madrugada, o paciente teve nova parada cardíaca e não foi reanimado. O óbito foi num sábado, mas, ainda assim, os familiares informaram a psicóloga, que não pôde participar do funeral tendo em vista que ele ocorreu em uma cidade distante. Contudo, na semana seguinte, a profissional realizou contatos telefônicos com uma das cuidadoras e também um atendimento ao filho, que se mostrava tranquilo e assim também referia estar sua irmã.

\section{Últimas palavras}

Findado o atendimento, o "vai-e-vem" do paciente em protocolo de cuidados paliativos foi um intenso aprendizado para a equipe. Todos se modificaram. Neste processo, ficou demarcada a importância do respeito aos desejos, opiniões, crenças e história de vida de Pedro e de sua família; a busca pela resolução de pendências emocionais, espirituais e sociais; o cultivo de um vínculo de amizade e confiança, possibilitando aos paciente, familiares e cuidadoras sentirem-se acolhidos, seguros e aliviados psíquica e espiritualmente com a presença da equipe (Incontri, 2011).

Em todo este processo, além do trabalho de suporte ao paciente e à família para o enfrentamento do adoecimento e finitude, o acompanhamento psicológico foi fonte de mediação e ligação entre os atendimentos realizados pelos demais profissionais. Realizou-se, assim, o apoio também às equipes assistenciais para a tomada de decisões, visando principalmente garantir que a autonomia do paciente fosse preservada e suas escolhas fossem incluídas nas condutas adotadas.

E tudo parece ter, apesar das diversas reviravoltas, contribuído para que o paciente se desligasse da vida e para que os filhos pudessem estar tranquilos com relação às decisões tomadas. Além deles, também sua esposa e cuidadoras, que algumas vezes voltaram ao hospital para rever as equipes, mostravam um enfrentamento sem complicações do luto pela perda. Neste sentido, ter criado condições de promover o luto antecipatório, possibilitando ao paciente fazer suas despedidas, deu a oportunidade de morte serena e a promoção de um luto saudável à família (Macieira \& Palma, 2011). O trabalho em cuidados paliativos e as intervenções em Psicologia contribuíram, assim, para que Pedro falecesse tranquilo e "a salvo".

\section{Referências}

Academia Nacional de Cuidados Paliativos - ANCP. (2012). Manual de cuidados paliativos. Rio de Janeiro, RJ: o autor.

Breitbart, W. S. (2011). Retidão, integridade e cuidado: como viver diante da morte. In F. S. Santos, Cuidados paliativos: diretrizes, humanização e alívio de sintomas. (pp. 131-140). São Paulo, SP: Atheneu.

Conselho Federal de Psicologia. (2001). Resolução CFP no 02/01. Altera e regulamenta a Resolução CFP no 014/00 que institui o título profissional de especialista em psicologia e o respectivo registro nos Conselhos Regionais.. Brasília, DF: o autor.

Corrêa, S. R. (2011). O cuidar do moribundo nas últimas 48 horas. In F. S. Santos, Cuidados paliativos: diretrizes, humanização e alívio de sintomas (pp. 625-635). São Paulo, SP: Atheneu.

Costa Filho, R. C., Costa, J. L. F, Gutierrez, F. L. B. R., \& Mesquita, A. F. (2008). Como implementar cuidados paliativos de qualidade na unidade de terapia intensiva. Revista Brasileira de Terapia Intensiva, 20(1), 88-92. https://doi.org/10.1590/S0103-507X2008000100014

GIL, A. C. (2008). Métodos e técnicas de pesquisa social (6a ed.). São Paulo, SP: Atlas.

Incontri, D. (2011). Equipes interdisciplinares em cuidados paliativos - religando o saber e o sentir. In F. S. Santos, Cuidados paliativos: diretrizes, humanização e alívio de sintomas (pp. 141-148). São Paulo, SP: Atheneu.

Kóvacs, M. J. (2007). Perdas e o processo de luto. In D. Incontri, \& F. S. Santos (Org.), A arte de morrer: visões plurais (pp. 217-238). Bragança Paulista, SP: Comenius. 
Kübler-Ross, E. (2011). Sobre a morte e o morrer (9a ed.). São Paulo, SP: Martins Fontes.

Macieira, R. C., \& Palma, R. R. (2011). Psico-oncologia e cuidados paliativos. In F. S. Santos, Cuidados paliativos: diretrizes, humanização e alívio de sintomas (pp. 323-330). São Paulo, SP: Atheneu.

Medeiros, G. A. (2002). Por uma ética na saúde: algumas reflexões sobre a ética e o ser ético na atuação do psicólogo. Psicologia: Ciência e Profissão, 22(1), 30-37. https:// doi.org/10.1590/S1414-98932002000100005

Menezes, R. A. (2011). Tomadas de decisão, poder médico e sentimentos no último período de vida. In F. S. Santos, Cuidados paliativos: diretrizes, humanização e alivio de sintomas (pp. 193-200). São Paulo, SP: Atheneu.

Santos, F. S. (2011). Cuidados paliativos em geriatria. In F. S. Santos, Cuidados paliativos: diretrizes, humanização e alívio de sintomas (pp. 453-473). São Paulo, SP: Atheneu.

Schimidt, M. D., \& Lima, M. A. D. S. (2004). Acolhimento e vínculo em uma equipe do Programa Saúde da Família. Cadernos de Saúde Pública, 20(6), 1487-94. https://doi.org/10.1590/S0102-311X2004000600005

Serralta,F.B., Nunes, M.L.T., \&Eizirik,C.L. (2011).Consideraçõesmetodológicassobreoestudodecaso napesquisaem psicoterapia. EstudosdePsicologia(Campinas),28(4),501-510.https://doi.org/10.1590/S0103-166X2011000400010

Silva, C. S., Siqueira, J., Stroppa, A., \& Moreira-Almeida, A. (2011). Coping espiritual e cuidados paliativos. In F. S. Santos, Cuidados paliativos: diretrizes, humanização e alívio de sintomas (pp. 175-182). São Paulo, SP: Atheneu.

Yamaguchi, A. M. \& Oliveira, I. V. (2011). Cuidados paliativos na assistência domiciliar. In F. S. Santos, Cuidados paliativos: diretrizes, humanização e alívio de sintomas (pp. 31-38). São Paulo, SP: Atheneu.

\section{Fabíola Langaro}

Mestre em Psicologia pela Universidade Federal de Santa Catarina - UFSC. Especialista em Psicologia da Saúde e Hospitalar pela FPP. Psicóloga Hospitalar do Centro Hospitalar Unimed. Docente da Faculdade Guilherme Guimbala/Associação Catarinense de Ensino, Joinville, SC, Brasil.

E-mail: flangaro@hotmail.com

Endereço para envio de correspondência:

Centro Hospitalar Unimed Joinville, Rua Orestes Guimarães, 905, América. Joinville - SC, Brasil.

Recebido 29/06/2014

Aprovado 16/11/2016

Received 06/29/2014

Approved 11/16/2016

Recibido 29/06/2014

Aceptado 16/11/2016

Como citar: Langaro, F. (2017). “Salva o Velho!": relato de atendimento em psicologia hospitalar e cuidados paliativos. Psicologia: Ciência e Profissão, 37(1): 224-235. https://doi.org/10.1590/1982-3703000972014

How to cite: Langaro, F. (2017). "Save the Eldery!": care report in health psychology and palliative care. Psicologia: Ciência e Profissão, 37(1): 224-235. https://doi.org/10.1590/1982-3703000972014

Cómo citar: Langaro, F. (2017). “Salva al Adulto Mayor!”: informe de atención en psicología de la salud y cuidados paliativos. Psicologia: Ciência e Profissão, 37(1):224-235. https://doi.org/10.1590/1982-3703000972014 